\title{
An assessment of the quality of neonatal care in the Solomon Islands
}

\author{
Dr S Tosif MBBS FRACP ${ }^{1}$, Dr Titus Nasi ${ }^{2}$, Dr Amy Gray ${ }^{1}$, Mr Nahad Sadr-
} Azodi $^{3}$, Dr Divi Ogaoga ${ }^{4}$, Prof T Duke MD FRACP FCICM ${ }^{1}$

\section{Original Article}

\begin{abstract}
Affiliations:
(1) Centre for International Child Health, University of Melbourne, Murdoch Children's Research Institute, Royal Children's Hospital Melbourne

(2) Head of Paediatrics Department, National Referral Hospital, Honiara

(3) United Nations Children's Fund, Suva, Fiji

(4) Director, Reproductive and Child Health Division, Ministry of Health and Medical Services, Solomon Islands
\end{abstract}

\section{Corresponding author:}

Dr Shidan Tosif

Centre for International Child Health

University of Melbourne

50 Flemington $\mathrm{Rd}$

Parkville VIC 3052 Australia

Phone -61-3-9345-6160

Fax -61-3-9345-5938

Email shidan.tosif@rch.org.au

\section{Author contact details:}

Dr Titus Nasi

Head of Paediatrics Department

National Referral Hospital

P.O. Box 349

Honiara

Solomon Islands

Phone: (677) 23600

Email NTitus@nrh.gov.sb

Dr Amy Gray

Centre for International Child Health

This is the author manuscript accepted for publication and has undergone full peer review but has not been through the copyediting, typesetting, pagination and proofreading process, which may lead to differences between this version and the Version of Record. Please cite this article as doi: $10.1111 /$ jpc.13686

This article is protected by copyright. All rights reserved. 
University of Melbourne

50 Flemington $\mathrm{Rd}$

Parkville VIC 3052 Australia

Phone -61-3-9345-6160

Fax -61-3-9345-5938

Email amy.gray@rch.org.au

Dr Divi Ogaoga

Director

Reproductive and Child Health Division

Ministry of Health and Medical Services, Solomon Islands

P.O. Box 349

Honiara

Solomon Islands

Ph.: (677) 28610

Fax: (677) 20085

Email: DOgaoga@moh.gov.sb

Mr Nahad Sadr-Azodi

Acting Chief of Child Survival and Development

United Nations Children's Fund

$3^{\text {rd }}$ Floor, FDB Building

360 Victoria Parade, Suva, FIJI

Email: nsadrazodi@unicef.org

Telephone: (679) 3300439

Facsimile: (679) 3301667

Professor Trevor Duke

Centre for International Child Health

University of Melbourne

50 Flemington $\mathrm{Rd}$

Parkville VIC 3052 Australia

Phone -61-3-9345-6160

Fax -61-3-9345-5938

Email trevor.duke@rch.org.au 


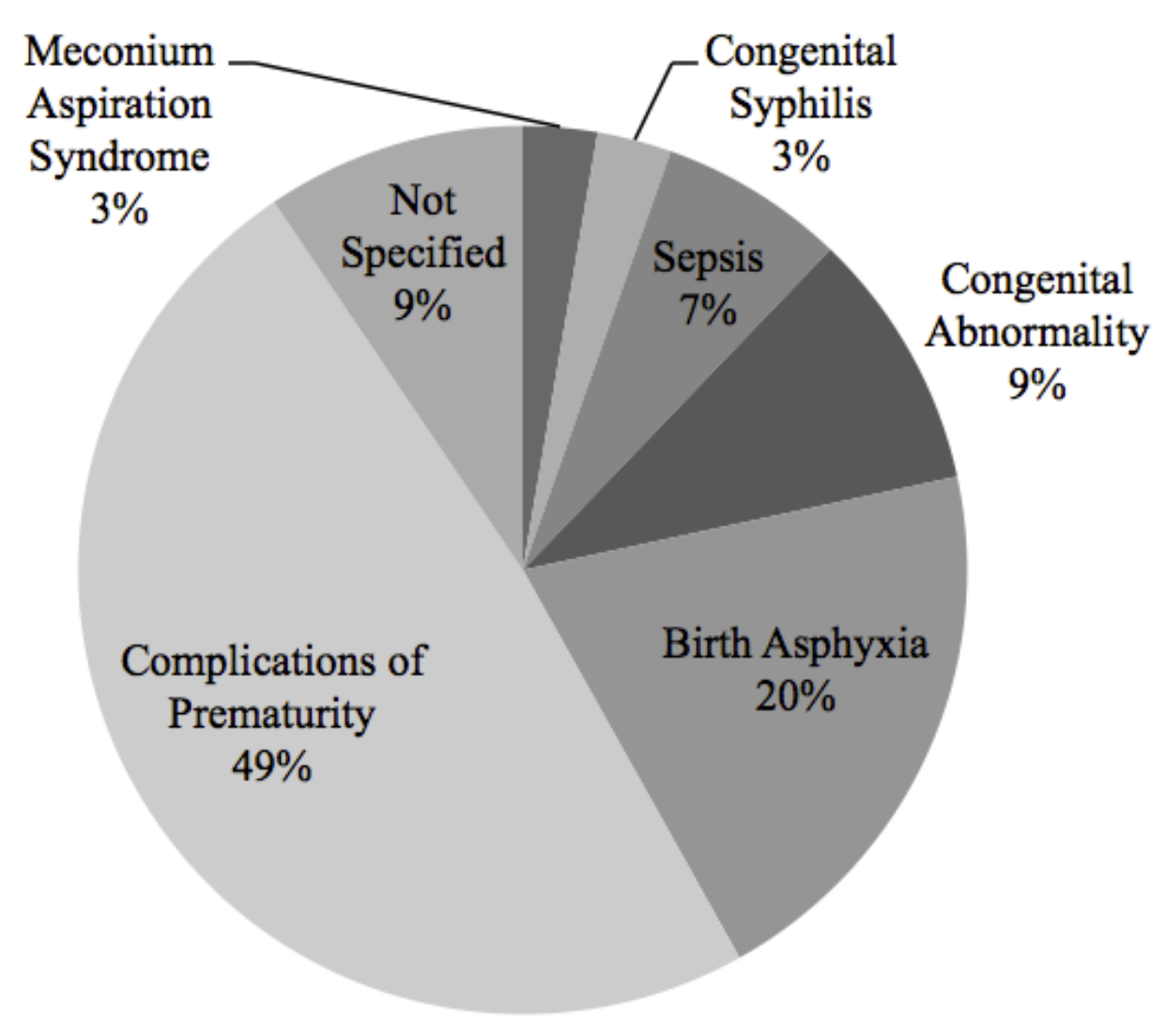

Figure 1.tiff

This article is protected by copyright. All rights reserved. 


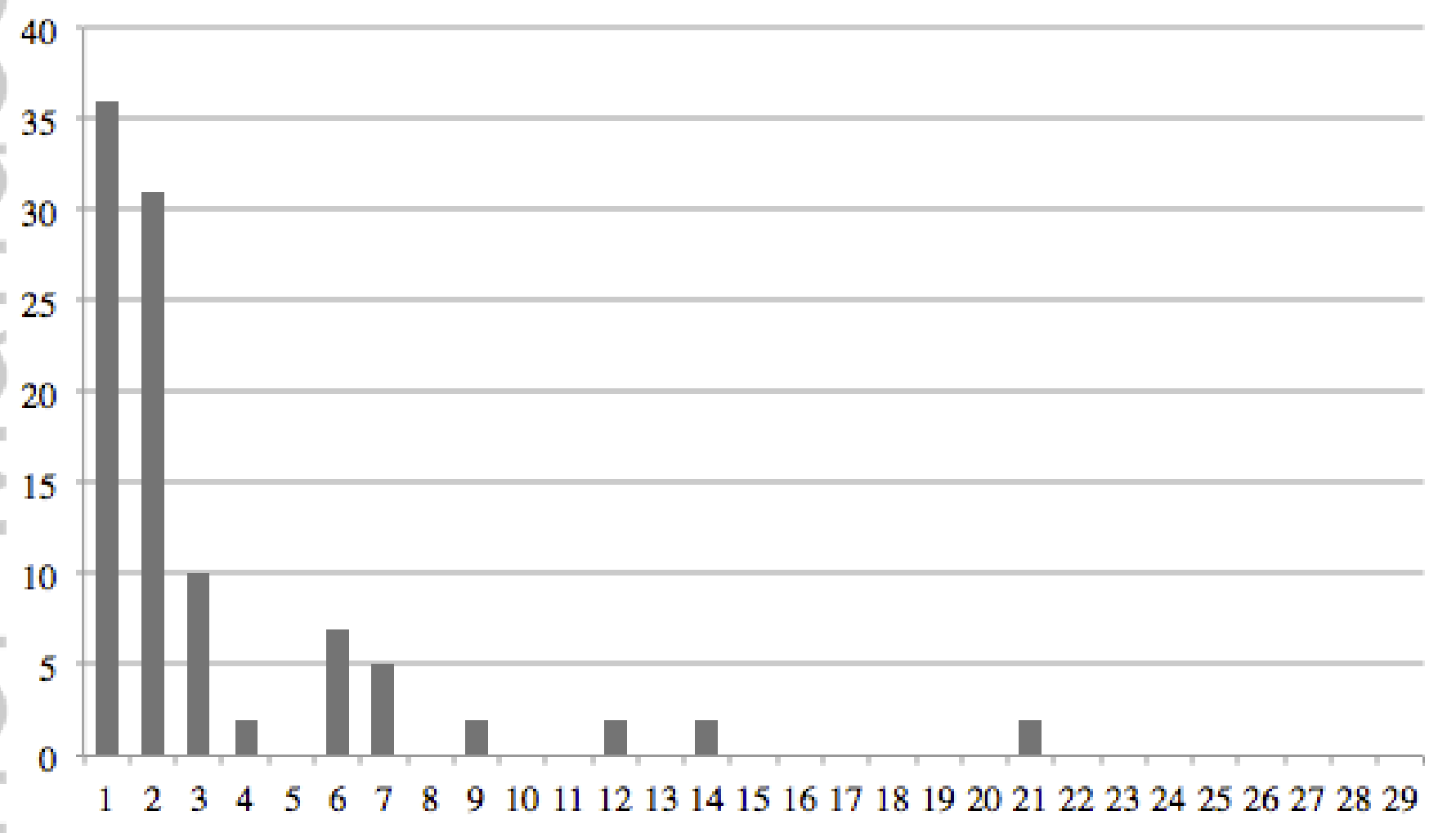

Figure 2.tiff

This article is protected by copyright. All rights reserved. 
An assessment of the quality of neonatal care in the Solomon Islands

This article is protected by copyright. All rights reserved. 
Keywords: developing countries, neonatal assessment, neonatal mortality, quality of care, small island nation, western pacific

What is already known on the topic:

1. Improving newborn mortality is a priority in The Sustainable Development Goals and the Action Plan for Healthy Newborns in the Western Pacific

2. The Solomon Islands is a low-middle income country in the Western Pacific with a high neonatal mortality rate. Neonatal mortality rates have improved slower than child mortality and now constitute $44 \%$ of deaths in children under the age of 5 years.

3. There is a high rate of institutional delivery ( $95 \%$ urban, $84 \%$ rural), but the quality of newborn care at these facilities is not known.

What this paper adds:

1. Essential medications and basic equipment were generally available at the facilities.

2. Barriers to newborn care were workforce limitations and expertise, equipment organisation, poor technical maintenance and lack of infection control measures.

3. At the National Referral Hospital in Honiara there is a high rate of stillbirths, and most neonatal deaths occur in the first 3 days of life. 


\section{Introduction}

Ending preventable newborn deaths is a global and regional priority in Oceania. Mortality in this age group was estimated to account for $44 \%$ of under- 5 deaths in the Solomon Islands in $2013^{1}$. Whilst there have been significant improvements in mortality for children under the age of 5 years, newborn mortality has decreased at a much slower rate, and improving outcomes for newborns is a priority for the Sustainable Development Goal agenda. Poor progress is reflective of challenges in access to facilities providing quality care for newborns, an objective inseparable from improving maternal health ${ }^{2,3}$. The majority of newborn deaths occur in the first three days of life despite simple, cost effective interventions existing to prevent them ${ }^{1}$.

The Solomon Islands is a lower-middle-income country and small island nation, facing unique challenges in the provision of health care across a large geographical area serviced by a small workforce. It is recognised as a fragile state ${ }^{4}$, and over the past 15 years, efforts to improve health care have been challenged by economic vulnerability, social unrest and a series of complex emergencies. The Solomon Islands remains at high risk of susceptibility to extreme natural events ${ }^{5}$.

Unlike in many countries facing such challenges, in Solomon Islands there is a high rate of institutional delivery of newborns $(95 \% \text { urban, } 84 \% \text { rural })^{6}$. There are improving rates of routine immunisation and proportion of exclusively breastfed infants under 6 months of age ${ }^{7}$. The Solomon Islands Ministry of Health and Medical Services (MHMS) is in the process of establishing Universal Health Coverage and together with development partners (World Health Organisation, United Nations International Children's Fund) aims to identify and improve the types of health facilities available and improve core services, infrastructure and equipment for newborns.

As the Solomon Islands embarks on efforts to improve and scale up newborn care, an understanding of the baseline quality of care is required. Previous studies assessing the quality of care for children in the Solomon Islands ${ }^{8}$ and neonates in other countries ${ }^{9}$ have illustrated the links between assessments, health policy and quality improvement activities. Information regarding gaps in standards of care, referral guidelines, infrastructure (basic equipment and medications for neonatal care) and health systems for neonatal services are essential to understand, shape and prioritise interventions. The purpose of this study was to assess newborn services and describe the obstacles to improving newborn quality of care. 


\section{Methods}

\section{Study Sites}

A purposeful sample of health facilities was chosen following consultation with the Solomon Islands MHMS, and paediatricians from the National Referral Hospital (NRH). The provinces in which hospitals were selected account for $80 \%$ of the population of the country. They were chosen as being representative due to size and location, and as the sites with the highest number of births. Four provincial hospitals (Gizo, Western Province, Kilu'ufi, Malaita Province, Kirakira, Makira-Ulawa Province and Good Samaritan Hospital, Guadalcanal Province) and the NRH (Honiara, Capital Territory) were systematically assessed over 1-2 days per site.

\section{[INSERT Table 1: Demographics of hospitals assessed, 2014]}

\section{Data Collection}

An audit of 12 months of birth and neonatal admissions for 2014 at NRH was conducted, by extraction of data from ward logbooks. Data collected included number of births, stillbirths, and neonatal deaths from the labour ward. Birth weight, duration of admission, diagnosis, treatment, survival, and length of stay were retrieved from the NRH newborn nursery logbooks. The outcomes of interest were diagnoses, causes of mortality, rates of stillbirth, low birth weight and age at death. Data were entered into Excel (Microsoft 2011) for analysis. Descriptive statistics were calculated for clinical characteristics and neonatal outcomes. A facility based neonatal mortality rate was calculated by combining data from neonatal and labour ward logbooks, removing duplicates, and out-born neonates.

Site inspections were conducted together with the provincial hospital administrator and senior nursing staff in May 2015 and June 2016. The assessment team comprised a paediatrician from NRH (TN) and two NRH paediatric registrars (JS, SL) accompanied by a visiting paediatrician (ST). An assessment tool adapted for the local context from the WHO assessment tool for hospital quality of care was used ${ }^{10}$. The assessment covered all facility areas where newborn care was delivered (labour ward, postnatal ward, neonatal, children's wards, and emergency and outpatients departments). Data were collected through observation of facilities and equipment and review of ward admission records for the preceding 12 months. Interviews with available health care workers were used to fill in gaps in data, and to provide an opportunity to raise issues not covered elsewhere in the assessment. At the end of the assessment, health care workers were asked to discuss their priorities to improve newborn care. Data were entered into a standardised form and compared between sites to identify common themes, specifically regarding indicators important for newborn care.

This study was approved by the Solomon Islands Health Research and Ethics Review Board (project number HRE033/16) and the University of Melbourne Human Research Ethics Committee (HREC number 1646267.1). 


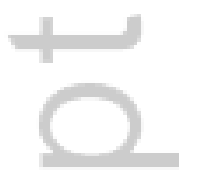




\title{
Results
}

The main findings of the hospital assessments are summarised in tables 2 and 3 . Basic equipment and supplies for the resuscitation and care of sick newborns, including bag and mask, oxygen source and pulse oximeters were generally available. However no site had these items ready and organised for routine and emergency newborn care in a resuscitation area. Facilities to support expressing and storing breast-milk, and items required for neonates with feeding difficulties (refrigerator for storage of expressed breast milk, cup/spoon) were limited. Apart from NRH, which was regularly overcrowded, physical space in the nurseries was adequate, with direct access for mothers. Most hospitals had access to running water. Electricity supplies were by mains power, which was erratic, with surges and blackouts occurring commonly. Backup generators were present at all sites but frequently failed at the two largest hospitals. With regards to infection control, hand sanitizer dispensers were present in each ward, but invariably empty.

\section{[INSERT Table 2: Hospital assessment for newborn indicators]}

\section{[INSERT Table 3: Availability of essential medications for newborn care]}

\begin{abstract}
Almost all paediatricians, and nurses with training in paediatrics were based at NRH, with only one other provincial hospital employing a paediatrician. Access to an on-call doctor after hours was affected predominantly by transport availability, with significant delay for paediatrician attendance at NRH. Almost all medications relevant for neonates were available at each nursery.
\end{abstract}

12 months of data from the NRH labour ward and nursery were analysed. At the labour ward, there were 5412 live births, 65 (1.2\%) fresh stillbirths, 96 (1.8\%) macerated stillbirths and 38 neonatal deaths. $688(12.7 \%)$ of births were low birth weight $(<2500 \mathrm{~g})$.

Over the same 12 months there were 779 nursery admissions with $68(8.7 \%)$ deaths. The final diagnosis for neonatal deaths was available for 61 neonates and is shown in figure $1.77 \%$ of deaths occurred in the first 3 days of life (see figure 2). Neonatal mortality increased with decreasing birth weight, with $6 \%$ mortality rate in neonates $>2500 \mathrm{~g}, 13 \%$ mortality in 1500 $2499 \mathrm{~g}, 35 \%$ mortality in $1000-1499 \mathrm{~g}$ and $80 \%$ mortality rate in neonates less than $1000 \mathrm{~g}$. The most common reasons for admission were infection/suspected sepsis $(46.5 \%)$, prematurity/low birth weight (22.2\%), infection (10.0\%), birth asphyxia $(7.7 \%)$, hypoglycaemia (5.3\%), and meconium aspiration (3.8\%). Total neonatal mortality at NRH was 16 per 1000 live births ( 89 / 5412). 
[INSERT Figure 1 Final diagnosis in neonatal deaths, NRH Nursery $(n=61)$ 2014]

[INSERT Figure 2 Age at death for newborns, by percentage, NRH Nursery $(\mathrm{n}=$ 61) in 2014]

Staff interviews and group discussions raised a number of concerns regarding structure and process aspects of delivering neonatal care. The priority themes and challenges are described in textbox 1.

This article is protected by copyright. All rights reserved. 


\section{Discussion}

This study describes an assessment of four provincial hospitals and the National Referral Hospital of the Solomon Islands, a small but widely dispersed island nation in the Western Pacific, based on standards of newborn care set out in WHO guidelines. Amongst these facilities, barriers to newborn care were equipment organisation, poor technical maintenance, and lack of infection control measures. Health workforce limitations were marked by few paediatric-trained nurses and lack of paediatricians outside of the capital. An assessment of NRH birth and nursery admissions showed high rates of stillbirth and early neonatal deaths. The neonatal mortality rate at NRH of 16 per 1000 live births is within reach of the SDG target of 12 per 1000 live births ${ }^{11}$. However, there are at least as many stillbirths as neonatal deaths, which need to be accounted for in reaching targets to improve perinatal care.

The general availability of essential medications, oxygen, and electricity was positive, and constitutes an improvement since an assessment in 2003 following 5 years of civil unrest ${ }^{8}$. However, maintenance and organisation of equipment was a problem. Empty hand sanitiser dispensers or hand hygiene not within working reach of patient care areas point to the lack of a system for replenishment, procurement and distribution, and lack of practical awareness of the importance of the basics of infection control. Whilst a bag and mask was present in each health facility, no hospital had an assembled, accessible bag and mask ready to use where neonates were born. This would lead to delays in initiation of resuscitation or recognition of resuscitation opportunities, which may contribute to high rates of stillbirth and early neonatal death found in our audit, as described in other settings ${ }^{12}$. Routine newborn care is reliant on few, but important pieces of equipment to be available in a timely manner. Resuscitation devices for newborns are listed as one of thirteen lifesaving commodities in the improvement of maternal, child and newborn health outcomes ${ }^{13}$.

The Solomon Islands is emerging from a period of social unrest, environmental and economic challenges, which have had an impact on health service delivery. As a small island nation, the Solomon Islands encounters challenges specific to this setting, such as high commodity and transport costs. Low staffing numbers, and the flow-on effects of strikes and low pay of nurses in particular, presents a challenge to workforce culture, quality and consistency of services. Training and maintenance of skills for such a dispersed population of health care workers, and births across a large number of facilities is logistically difficult and expensive. Sick neonates, whose conditions are fragile and where management is time sensitive, can face days of travel by road or sea, depending on prevailing weather conditions and transport availability such as hospital ambulances or boats.

Similar to our findings, missing or underutilised essential equipment, logistical difficulties and poor supply have been described in low-middle income countries as barriers to delivering newborn care ${ }^{14-16}$. Inadequate hygiene measures, documentation, staff knowledge and skills, and insufficient essential equipment are common themes ${ }^{16-19}$. In other assessments where essential equipment is available, other systemic factors such as hand hygiene, inadequately 
trained staff, poor routine care, documentation and prescribing practices impact on quality of newborn care, ${ }^{20,21}$ highlighting the need to focus beyond structural improvements.

The findings of the audit of admissions and neonatal mortality at NRH are consistent with those observed in low and middle income countries, where neonatal infections, birth asphyxia, complications of preterm death and congenital abnormalities account for the greatest disease burden in neonates ${ }^{22}$ and highlights that more specialised training is needed in this area. This specialised training needs to take into account the health workforce in the country. In countries like the Solomon Islands, this needs to include training of paediatric nurses with neonatal skills, as well as more training for non-specialist medical officers who will practice in remote areas. A high rate of stillbirths could represent missed opportunities for resuscitation of a newborn ${ }^{12}$, or the need for greater intra-partum monitoring ${ }^{23,24}$.

We identified health workforce problems such as skilled staffing shortages and high turnover in this assessment, an issue identified in other countries ${ }^{25,26}$. From our observation, knowledge and skills in recognition and management of the sick newborn was limited. Equipping health care workers with skills for resuscitation, and capacity to care for sick newborns in the first week and beyond are essential ${ }^{12,24,27}$. These training issues need to be considered when equipment is made available. Resuscitation training is proposed to reduce term intra-partum related deaths by up to $30 \%{ }^{28}$. Education programs focussing on this content were not consistently delivered in ways that will be effective, instead relying on oneoff trainings provided by external agencies. Past assessments of health care worker knowledge and skills in newborn care in low-middle income countries have also identified that many staff perform below competency levels ${ }^{29,30}$. Barriers in establishing supportive practices following birth such as with $\mathrm{KMC}$ require significant training time and resources ${ }^{9,31}$, and resuscitation skills can be affected by decrement in knowledge and skills with time, requiring a long term approach to quality improvement ${ }^{32,33}$.

Priorities to accelerate improvement in neonatal care need to focus on interventions around the time of birth, identification and treatment of infections, and intra-partum and birth complications $^{34}$. Greater emphasis should be placed on evidence based practices, which are known to improve outcomes in care of sick newborns, premature and low birth weight babies. These include nursing even very sick babies with their mothers for skin-to-skin contact to reduce hypothermia and to facilitate feeding, breast feeding or the use of expressed breast milk, prevention of hospital-acquired infections, basic respiratory support such as safe use of oxygen and CPAP, improving infection control and limiting invasive procedures that carry risks ${ }^{35,36}$. In addition to high quality routine birth care, specific attention is required towards sick and small newborns, and increased community-based postnatal care ${ }^{34}$. Simple interventions such as protocol-based management, enforcing hand hygiene and aseptic procedures, Early Essential Newborn Care, and abandoning unnecessary interventions can lead to a significant decline on mortality in hospitals with limited resources ${ }^{37}$. 
This study has several limitations. The selection of sites was not random, and whilst the largest provinces with highest birth rates were chosen, smaller provinces may face different challenges. In a small country however, five health facilities form a significant proportion of the Solomon Island's health service. Interviews with staff relied on the individuals present on the days of assessment, and may be affected by bias or recollection in reporting. Whilst ward admission logbooks were the most reliable source of information, some fields were unfilled and neonatal admissions or deaths may be underestimated as a result. This study focused on newborn quality of care, however more information regarding intra-partum monitoring and obstetric care is needed to describe factors during labour associated with stillbirth or poor neonatal outcomes.

\section{Conclusion}

This assessment highlights some of the challenges to newborn quality of care in the Solomon Islands. Neonatal outcomes are characterised by high rates of stillbirth, immediate and early neonatal death, with a high contribution from premature and birth asphyxiated infants. Following substantial improvements in child survival, specific attention is now required to improve newborn outcomes through improvement in routine newborn care practices, resuscitation and specialised newborn skills, technical maintenance and a focus on infection control in the Solomon Islands.

\section{Acknowledgments}

We would like to thank MHMS and the NRH Department of Paediatrics for their contribution and support, and UNICEF Fiji for funding this assessment. 


\section{References}

1. WHO. Action plan for healthy newborn infants in the Western Pacific region (20142020). Geneva: Available online:

https://www.unicef.org/eapro/regional action plan new born infants.pdf [last accessed May 2017]; 2014.

2. Austin A, Langer A, Salam RA, Lassi ZS, Das JK, Bhutta ZA. Approaches to improve the quality of maternal and newborn health care: an overview of the evidence. Reprod Health. 2014;11 Suppl 2:S1.

3. Knippenberg R, Lawn JE, Darmstadt GL, et al. Systematic scaling up of neonatal care in countries. Lancet. 2005;365(9464):1087-1098.

4. The World Bank, List of Fragile and Conflict Affected Situations FY16. 2016. Available online: http://data.worldbank.org/region/fragile-and-conflictaffected-situations [last accessed 20th November 2016].

5. United Nations University: Insitute for Environment and Human Security. World Risk Report. Available online: https://i.unu.edu/media/ehs.unu.edu/news/4070/11895.pdf [last accessed May 2017]; 2014.

6. UNICEF. The State of the World's Children 2016, Geneva. Available online http://www.unicef.org/publications/files/UNICEF SOWC 2016.pdf [last accessed November 2016]. 2016.

7. UNICEF and World Health Organisation. Countdown to 2015: A Decade of Tracking Progress for Maternal, Newborn and Child Survival The 2015 Report. Available online: http://countdown2030.org/reports-and-articles/2015-finalreport [last accessed May 2017]2015.

8. Auto J, Nasi T, Ogaoga D, Kelly J, Duke T. Hospital services for children in the Solomon Islands: rebuilding after the civil conflict. J Paediatr Child Health. 2006;42(11):680-687.

9. Aluvaala J, Nyamai R, Were F, et al. Assessment of neonatal care in clinical training facilities in Kenya. Arch Dis Child. 2015;100(1):42-47.

10. WHO Regional Office for Europe. Making Pregnancy Safer Assessment tool for the quality of hospital care for mothers and newborn babies. Available online: http://www.euro.who.int/ data/assets/pdf file/0008/98792/E93128.pdf [last accessed May 2017].

11. United Nations. Sustainable Development Goals: Goal 3. New York 2015 https://sustainabledevelopment.un.org/ [last accessed May 2017].

12. Ersdal HL, Mduma E, Svensen E, Perlman JM. Early initiation of basic resuscitation interventions including face mask ventilation may reduce birth

This article is protected by copyright. All rights reserved. 
asphyxia related mortality in low-income countries: a prospective descriptive observational study. Resuscitation. 2012;83(7):869-873.

13. United Nations Commission on Life-Saving Commodities for Women and Children. Commissioners' Report. Available online: https://www.unfpa.org/sites/default/files/pub-pdf/Final UN Commission Report 14sept2012.pdf [last accessed May 2017]2012.

14. Pavitra M, Baya K, Sharad S, Rajiv B, Anju P, Rajesh K. Assessment of implementation of integrated management of neonatal and childhood illness in India. Journal of Health, Population and Nutrition. 2011;29(6):629-638.

15. Pradhan NA, Rizvi N, Sami N, Gul X. Insight into implementation of facility-based integrated management of childhood illness strategy in a rural district of Sindh, Pakistan. Glob Health Action. 2013;6:20086.

16. Trevisanuto D, Cavallin F, Arnolda G, et al. Equipment for neonatal resuscitation in a middle-income country: a national survey in Vietnam. BMC Pediatr. 2016;16:1-8.

17. Owens L, Semrau K, Mbewe R, et al. The state of routine and emergency obstetric and neonatal care in Southern Province, Zambia. Int J Gynaecol Obstet. 2015;128(1):53-57.

18. English M, Ntoburi S, Wagai J, et al. An intervention to improve paediatric and newborn care in Kenyan district hospitals: understanding the context. Implement Sci. 2009;4:42.

19. Vesel L, Manu A, Lohela TJ, et al. Quality of newborn care: a health facility assessment in rural Ghana using survey, vignette and surveillance data. BMJ Open. 2013;3:e002326(5).

20. Mirkuzie AH, Sisay MM, Reta AT, Bedane MM. Current evidence on basic emergency obstetric and newborn care services in Addis Ababa, Ethiopia; a cross sectional study. BMC Pregnancy And Childbirth. 2014;14:354-354.

21. Kim YM, Ansari N, Kols A, et al. Assessing the capacity for newborn resuscitation and factors associated with providers' knowledge and skills: a cross-sectional study in Afghanistan. BMC Pediatr. 2013;13:140.

22. Lawn JE, Kerber K, Enweronu-Laryea C, Massee Bateman O. Newborn survival in low resource settings--are we delivering? Bjog. 2009;116 Suppl 1:49-59.

23. Kidanto H, Msemo G, Mmbando D, Rusibamayila N, Ersdal H, Perlman J. Clinical article: Predisposing factors associated with stillbirth in Tanzania. International Journal of Gynecology and Obstetrics. 2015;130:70-73.

24. Ersdal HL, Singhal N. Resuscitation in resource-limited settings. Seminars in Fetal and Neonatal Medicine. 2013;18(6):373-378. 
25. Faqir M, Zainullah P, Tappis H, Mungia J, Currie S, Kim YM. Availability and distribution of human resources for provision of comprehensive emergency obstetric and newborn care in Afghanistan: a cross-sectional study. Confl Health. 2015;9:9.

26. Enweronu-Laryea C, Dickson KE, Moxon SG, et al. Basic newborn care and neonatal resuscitation: a multi-country analysis of health system bottlenecks and potential solutions. BMC Pregnancy and Childbirth. 2015;15(Suppl. 2):S4.

27. Wall SN, Lee ACC, Carlo W, et al. Reducing intrapartum-related neonatal deaths in low- and middle-income countries - what works? Semin Perinatol. 2010;34(6):395-407.

28. Lee AC, Cousens S, Wall SN, et al. Neonatal resuscitation and immediate newborn assessment and stimulation for the prevention of neonatal deaths: a systematic review, meta-analysis and Delphi estimation of mortality effect. BMC Public Health. 2011;11 Suppl 3:S12.

29. Ariff S, Soofi SB, Sadiq K, et al. Evaluation of health workforce competence in maternal and neonatal issues in public health sector of Pakistan: an Assessment of their training needs. BMC health services research. 2010;10:319.

30. Malhotra S, Zodpey SP, Vidyasagaran AL, et al. Assessment of essential newborn care services in secondary-level facilities from two districts of India. Journal of Health, Population and Nutrition. 2014;32:130.

31. Bergh AM, Kerber $\mathrm{K}, \mathrm{Abwao} \mathrm{S}$, et al. Implementing facility-based kangaroo mother care services: lessons from a multi-country study in Africa. BMC Health Serv Res. 2014;14:293.

32. Reisman J, Arlington L, Jensen L, Louis H, Suarez-Rebling D, Nelson BD. Newborn Resuscitation Training in Resource-Limited Settings: A Systematic Literature Review. Pediatrics. 2016;138((2) e20154490).

33. Mduma E, Ersdal H, Svensen E, Kidanto H, Auestad B, Perlman J. Frequent brief on-site simulation training and reduction in 24-h neonatal mortality--an educational intervention study. Resuscitation. 2015;93:1-7.

34. Lawn JE, Blencowe H, Oza S, et al. Every Newborn: progress, priorities, and potential beyond survival. Lancet. 2014;384(9938):189-205.

35. Boo NY, Puah CH, Lye MS. The role of expressed breastmilk and continuous positive airway pressure as predictors of survival in extremely low birthweight infants. J Trop Pediatr. 2000;46(1):15-20.

36. Ho JJ, Chang AS. Changes in the process of care and outcome over a 10-year period in a neonatal nursery in a developing country. J Trop Pediatr. 2007;53(4):232-237. 
37. Agarwal R, Agarwal K, Acharya U, Christina P, Sreenivas V, Seetaraman S. Impact of simple interventions on neonatal mortality in a low-resource teaching hospital in India. J Perinatol. 2007;27(1):44-49.

This article is protected by copyright. All rights reserved. 


\begin{tabular}{|c|c|c|c|c|c|}
\hline Hospital & NRH & Kilu'ufi & Gizo & Kirakira & Good Samaritan \\
\hline Province & Honiara town council & Malaita & Western & Makira-Ulawa & Guadalcanal \\
\hline $\begin{array}{l}\text { Province } \\
\text { population }\end{array}$ & 64,609 & 137,596 & 76,649 & 40,419 & 93,613 \\
\hline $\begin{array}{l}\text { Provincial births } \\
\text { (2013) }\end{array}$ & 5561 & 3123 & 2283 & 1234 & 1443 \\
\hline $\begin{array}{l}\text { Provincial } \\
\text { hospital births } \\
(2013)\end{array}$ & 5554 & 953 & 587 & 405 & 626 \\
\hline $\begin{array}{l}\text { Travel time to } \\
\text { NRH }\end{array}$ & - & 8hrs (boat) & 48hrs (boat) & 24hrs (boat) & $1 \mathrm{hr}$ (drive) \\
\hline $\begin{array}{l}\text { Mean births per } \\
\text { month (range) }\end{array}$ & $451(388-514)$ & $88(71-102)$ & $53(35-77)$ & $34(23-44)$ & $56(43-67)$ \\
\hline $\begin{array}{l}\text { Special care } \\
\text { nursery }\end{array}$ & Yes & Yes & Yes & Yes & No \\
\hline $\begin{array}{l}\text { Capacity } \\
\text { (neonatal beds) }\end{array}$ & 22 & 6 & 10 & 2 & N/A \\
\hline $\begin{array}{l}\text { Mean nursery } \\
\text { admissions per } \\
\text { month (range) }\end{array}$ & $65(44-84)$ & $11(6-16)$ & $6(2-9)$ & $3(2-3)$ & N/A \\
\hline
\end{tabular}


Table 1: Hospital demographics (2014)

This article is protected by copyright. All rights reserved. 


\section{Facility}

NRH

Kilu'ufi

Equipment/Supplies

Oxygen Source

Cylinder +

concentrator

Oximeter with neonatal

probes

Overhead warmers

Phototherapy system

Self-inflating resuscitation

bags

Thermometers

Stethoscopes

Glucometers + strips

Nasogastric tubes sizes 6, 8, Yes

$10,12 \mathrm{~F}$

Cylinder

Yes

Yes

Yes
Gizo

Kirakira

Good Samaritan

Concentrator

Cylinder +

Cylinder + concentrator

concentrator (not in

use)

1

1

2

0

2

Yes Yes

\section{0}

1

2

Yes

Yes

Yes

Yes
Yes

Yes

Yes

Yes 


\section{Facilities for Mothers}

24-hr access to newborn

Yes

Yes

Yes

Yes

Yes

Cups/spoons for feeding

\section{Ward Organisation}

Bag and bask assembled and No

within reach of resuscitation

area

Overcrowding

Direct line of sight to high dependency neonates

Designated resuscitation

area

State of building repair and maintenance
Yes

Yes

Satisfactory
No

Yes

Yes

No

Yes (if nurse allocated)

Yes

No

Excellent
Yes

$\mathrm{N} / \mathrm{A}$

$\mathrm{N} / \mathrm{A}$

No

Satisfactory 


\begin{tabular}{|c|c|c|c|c|c|}
\hline $\begin{array}{l}\text { Continuous electricity } \\
\text { supply }\end{array}$ & No & No & Yes & Yes & No \\
\hline Continuous running water & Yes & Yes & Yes & Yes & Yes \\
\hline \multicolumn{6}{|l|}{ Infection Control } \\
\hline Wash basin, soap, water & No & No & No & No & Yes \\
\hline $\begin{array}{l}\text { Alcohol hand gel dispenser } \\
\text { and supply }\end{array}$ & No & Yes & Yes & No & No \\
\hline \multicolumn{6}{|l|}{ Staffing } \\
\hline Paediatricians & 3 & 1 & 0 & 0 & 0 \\
\hline Paediatric Nurse & $>10$ & 0 & $\begin{array}{l}1 \text { (not on clinical } \\
\text { duties) }\end{array}$ & 0 & 0 \\
\hline Staff availability after hours & $\begin{array}{l}\text { Paediatricians } \\
\text { available on call, } 3 \\
\text { nurses available at } \\
\text { night }\end{array}$ & $\begin{array}{l}1 \text { on-call doctor, } 1-2 \\
\text { nurses per night }\end{array}$ & $\begin{array}{l}1 \text { on-call doctor } \\
\text { during night, } 2 \\
\text { midwives per } \\
\text { overnight shift. }\end{array}$ & $\begin{array}{l}1 \text { midwife per shift, } \\
1 \text { paediatric nurse, } \\
\text { on-call doctor } \\
\text { overnight }\end{array}$ & 1 midwife, 1 nurse \\
\hline $\begin{array}{l}\text { First responder to } \\
\text { resuscitation after hours }\end{array}$ & Nurse & Midwife & Midwife & Midwife & Nurse/Midwife \\
\hline How is senior staff called for & Mobile phone & Mobile phone & Mobile phone & Mobile phone & $\mathrm{N} / \mathrm{A}$ \\
\hline
\end{tabular}


in emergency

Time for senior doctor to

arrive after hours?
60-90 minutes

depending on

availability of

hospital transport 5-15mins

$<30$ minutes

5-10minutes

No doctor available

Table 2: Hospital assessment for newborn indicators 


\begin{tabular}{|c|c|c|c|c|c|}
\hline & NRH & Kilu'ufi & Gizo & Kirakira & $\begin{array}{l}\text { Good } \\
\text { Samaritan }\end{array}$ \\
\hline Adrenaline & Yes & Yes & Yes & Yes & Yes \\
\hline Aminophylline & Yes & Yes & Yes & Yes & Yes \\
\hline Ampicillin & Yes & Yes & Yes & Yes & Yes \\
\hline Benzylpenicillin & Yes & Yes & Yes & Yes & Yes \\
\hline $\begin{array}{l}\text { Cefotaxime or } \\
\text { Ceftriaxone }\end{array}$ & Yes & Yes & No & No & No \\
\hline Chloramphenicol & Yes & Yes & Yes & Yes & Yes \\
\hline Gentamicin & Yes & Yes & Yes & Yes & Yes \\
\hline Phenobarbitone & No & Yes & No & No & No \\
\hline $\begin{array}{l}\text { Tetracycline eye drops or } \\
\text { ointment }\end{array}$ & Yes & Yes & Yes & Yes & Yes \\
\hline
\end{tabular}

Table 3: Availability of essential medications for newborn care

This article is protected by copyright. All rights reserved. 
Structural: poor condition of buildings, equipment shortages (e.g. insufficient oximeters, oxygen supply interrupted, thermometers), lack of technical support and prolonged time for repairs and spare parts (e.g. for replacement of phototherapy light bulbs)

Organisational: high workloads, insufficient numbers of nurses for care of neonates, more specially trained paediatric nurses needed

Training needs: more practical training modes preferred, staff most in need of a specific skillset were often not invited to appropriate training sessions, more opportunities for clinical attachments wanted

Resuscitation: Concerns raised that a sense of urgency was not present in practice of immediate newborn care

Resources: More copies of references needed, guidelines most frequently cited need updating (e.g. Solomon Islands Standard Treatment Manual)

Textbox 1: Healthcare worker challenges and priorities in improving newborn care 


\section{University Library}

\section{- M M N E R VA A gateway to Melbourne's research publications}

Minerva Access is the Institutional Repository of The University of Melbourne

Author/s:

Tosif, S;Nasi, T;Gray, A;Sadr-Azodi, N;Ogaoga, D;Duke, T

Title:

Assessment of the quality of neonatal care in the Solomon Islands

Date:

2018-02-01

Citation:

Tosif, S., Nasi, T., Gray, A., Sadr-Azodi, N., Ogaoga, D. \& Duke, T. (2018). Assessment of the quality of neonatal care in the Solomon Islands. JOURNAL OF PAEDIATRICS AND CHILD HEALTH, 54 (2), pp.165-171. https://doi.org/10.1111/jpc.13686.

Persistent Link:

http://hdl.handle.net/11343/293452 